\title{
Long non-coding RNA LINC00511 promotes proliferation, invasion, and migration of non-small cell lung cancer cells by targeting miR-625-5p/GSPT1
}

\author{
Yue Cheng ${ }^{1 \#}$, Shiqiang Wang ${ }^{2 \#}$, Xiaosong $\mathrm{Mu}^{1 \#}$ \\ ${ }^{1}$ General Department, Chongqing University Cancer Hospital, Chongqing, China; ${ }^{2}$ Department of Neuro Oncology, Chongqing University Cancer \\ Hospital, Chongqing, China \\ Contributions: (I) Conception and design: All authors; (II) Administrative support: S Wang; (III) Provision of study materials or patients: X Mu; (IV) \\ Collection and assembly of data: Y Cheng; (V) Data analysis and interpretation: Y Cheng; (VI) Manuscript writing: All authors; (VII) Final approval \\ of manuscript: All authors. \\ \#These authors contributed equally to this work. \\ Correspondence to: Dr. Xiaosong Mu. General Department, Chongqing University Cancer Hospital, Chongqing 400030, China. Email: 1324015602@qq.com.
}

Background: Lung cancer is a malignant tumor with a high rate of mortality and metastasis. Recently, extensive research has shown that long non-coding RNAs (lncRNAs) play a crucial role in the development and progression of non-small cell lung cancer (NSCLC). In this paper, we aimed to explore the impact of long intergenic non-coding RNA 00511 (LINC00511) on the development and metastasis of NSCLC.

Methods: A dataset containing 501 lung squamous cell carcinoma (LUSC) samples and 49 normal samples was downloaded from The Cancer Genome Atlas (TCGA). The differential gene expression and prognostic potential of LINC00511 in LUSC were analyzed by "limma" in R software. Samples of tumor tissues and normal tissues from 67 patients with NSCLC were obtained, along with clinical features. NSCLC cell proliferation, cell cycle, migration, and invasion were detected by LINC00511 knockdown with Cell Counting Kit-8 (CCK-8), flow cytometry, wound-healing assay, and Transwell experiment. The regulatory relationship between LINC00511 and microRNA (miR)-625-5p, or between miR-625-5p and G1 to $\mathrm{S}$ phase transition 1 (GSPT1), was detected by luciferase reporter gene assay. LINC00511, miR-625-5p, and GSPT1 expression in tumor and normal tissues and cells was determined by real-time quantitative reverse transcription polymerase chain reaction (qRT-PCR) and western blot. A xenograft experiment in nude mice was performed. Ki67 and GSPT1 expression in the tumor tissues of the nude mice was assessed by immunohistochemistry.

Results: LINC00511 expression was clearly higher in the tumor tissues of the NSCLC patients than in normal tissues $(\mathrm{P}<0.001)$. High LINC00511 expression was related to larger tumor size, positive lymph node metastasis, advanced TNM stage, and a lower 5-year survival rate. Compared with those of the shNC group, the NSCLC cells of the shLINC00511 group had a prominently lower optical density (OD) 450 value at $72 \mathrm{~h}$, a lower percentage of cells in $\mathrm{S}$ phase, a higher relative wound width, and a lower invasive cell number $(\mathrm{P}<0.01$ or $\mathrm{P}<0.001)$. LINC00511 promoted GSPT1 expression via suppressing miR-625-5p. Compared with those of the shNC group, the nude mice of the shLINC00511 group had a much lower subcutaneous tumor volume and weight $(\mathrm{P}<0.05$ or $\mathrm{P}<0.001)$.

Conclusions: lncRNA LINC00511 promotes proliferation, invasion, and migration of NSCLC cells by targeting miR-625-5p/GSPT. LINC00511 may be a potential diagnostic marker and therapeutic target for NSCLC.

Keywords: Non-small cell lung cancer (NSCLC); LINC00511; miR-625-5p/GSPT; proliferation; invasion; migration 
Submitted Aug 02, 2021. Accepted for publication Nov 16, 2021.

doi: $10.21037 /$ tcr-21-1468

View this article at: https://dx.doi.org/10.21037/tcr-21-1468

\section{Introduction}

Non-small cell lung cancer (NSCLC), one of the major malignant tumors associated with cancer-related death worldwide, accounts for approximately $85 \%$ of all lung cancer patients (1). NSCLC is associated with high mortality, with metastasis as the leading cause of death. For patients initially diagnosed with NSCLC, the 5 -year survival rate is no more than $15 \%$ (2). Despite significant progress in NSCLC treatment technology over the past few decades, poor prognosis remains a major clinical problem. Clarifying the molecular mechanism responsible for the poor prognosis of NSCLC is the key to developing more effective treatments.

In recent years, molecular targeted therapy has advanced to the frontier of NSCLC research. However, patients with NSCLC face high costs, as most develop drug resistance within 1 to 2 years. Therefore, it is necessary to actively explore the pathogenesis of NSCLC and seek new targets for diagnosis and treatment (3). Long non-coding RNAs (lncRNAs), a type of noncoding RNA that is more than 200 nucleotides in length, have been found to play a vital role in the pathology of human cancers (4). Some lncRNAs have been found to be involved in the development of human malignant tumors, including in NSCLC tumorigenesis, and to have a nonnegligible effect on the prognosis of patients $(5,6)$. For example, long intergenic non-protein coding RNA 968 (LINC00968) expression level in the tumor tissues of patients with NSCLC is significantly increased. Through in vitro and in vivo experiments, it has been found that knockdown of LINC00968 greatly limits NSCLC cell proliferation and growth (7). Furthermore, AGAP2 antisense RNA 1 (AGAP2-AS1), HOXA11 antisense RNA (HOXA11-AS), nuclear enriched abundant transcript (NEAT1), and small nucleolar RNA host gene 1 (SNHG1) are abnormally upregulated in NSCLC, while growth arrest specific 5 (GAS5), GAS5 antisense RNA 1 (GAS5-AS1), and taurine upregulated gene 1 (TUG1) are prominently downregulated in NSCLC (8). These lncRNAs are all associated with the progression of NSCLC. Nevertheless, the molecular mechanism of other lncRNAs in NSCLC require more detailed elaboration.

LINC00511 is a recently identified lncRNA. Previous research has found upregulated expression of LINC00511 in pancreatic ductal adenocarcinoma, bladder cancer, tongue squamous cell carcinoma, and thyroid carcinoma (9-12). An overexpressed LINC00511 level is associated with adverse clinical features and poor prognosis. However, more research is needed to determine the exact molecular mechanism of LINC00511 in tumorigenesis and NSCLC progression. In this paper, we investigated the relationship between LINC00511 expression and NSCLC prognosis using clinical data and studied the effects of LINC00511 on NSCLC cell biology at the molecular level. Our results identified a potential new diagnostic marker and therapeutic target for NSCLC. We present the following article in accordance with the ARRIVE reporting checklist (available at http://dx.doi.org/10.21037/tcr-21-1468).

\section{Methods}

\section{The Cancer Genome Atlas (TCGA) analysis}

The data of LINC00511 expression levels in patients with lung squamous cell carcinoma (LUSC) were downloaded from TCGA database (https://portal.gdc.cancer.gov/). The difference in LINC00511 expression levels between tumor tissues $(n=501)$ and normal tissues $(n=49)$ was analyzed using the "limma" package in R [ fold change (FC) | $>1.0$ and $\mathrm{P}<0.05$; the $\mathrm{R}$ Foundation for Statistical Computing, Vienna, Austria].

\section{Patients and tissues}

To confirm the result from TCGA database, 67 patients who were diagnosed with NSCLC from April 2010 to July 2013 in Chongqing University Cancer Hospital were recruited into the study. Radical surgical resection was performed on these patients, and tissue samples (including normal tissues and tumor tissues) were obtained from each patient. All patients were first discovered to have NSCLC and had no history of other oncological diseases or prior chemotherapy or radiotherapy.

The study was conducted in accordance with the Declaration of Helsinki (as revised in 2013). The study was approved by the Ethics Committee of Chongqing University Cancer Hospital. Written informed consent was taken from all individual participants. 


\section{Cell lines}

The human bronchial epithelial cell line (16HBE) and 5 NSCLC cell lines (A549, NCIH1299, NCIH1650, NCIH1975, and NCIH460) were maintained in Dulbecco's Modified Eagle Medium (DMEM) containing 10\% fetal bovine serum (FBS) at $37^{\circ} \mathrm{C}, 5 \% \mathrm{CO}_{2}$. The cell lines were collected when the cells had grown to $80 \%$ confluence. All cell lines were purchased from the Cell Bank of the Chinese Academy of Sciences (Shanghai, China).

\section{Transfection}

Short hairpin RNA (shRNA) and scramble shRNA of LINC00511 (Genepharma Co., Ltd., Shanghai, China) were used to transfect A549 and NCIH1975 cells. Twentyfour hours before transfection, A549 and NCIH1975 cells in logarithmic growth phase were harvested and seeded in 6 -well plates $\left(1 \times 10^{5}\right.$ cell/well $)$ containing $1 \mathrm{~mL}$ DMEM medium (10\% FBS). The transfection operation was performed with Lipofectamine 3000 (Thermo Fisher Scientific, Waltham, MA, USA) after the medium in each well was replaced with fresh DMEM medium without FBS. After 6-hour culture at $37^{\circ} \mathrm{C}, 5 \% \mathrm{CO}_{2}$, those successfully transfected A549 and NCIH1975 cells were selected and placed in the shLINC00511 group or the shNC group depending on the transfection.

Similarly, the A549 cells also underwent transfection with microRNA-625-5p mimic (miR-625-5p mimic group), miR-625-5p negative control (NC; miR-625-5p NC group), LINC00511 overexpression vector (LINC00511 group), and empty vector (LIN-NC group) using Lipofectamine 3000 (Thermo Fisher Scientific). The A549 cells were subjected to cotransfection with LINC00511 overexpression vector and miR-625-5p mimic (LINC00511 + miR-625-5p mimic group). G1 to $\mathrm{S}$ phase transition 1 (GSPT1) shRNA and LINC00511 overexpression vectors were also used simultaneously to transfect the A549 cells (LINC00511 + shGSPT1 group). The transfectants involved in this experiment were obtained from Genepharma Co., Ltd. The cells stably transfected were collected and continuously cultured in DMEM medium (10\% FBS) at $37^{\circ} \mathrm{C}, 5 \% \mathrm{CO}_{2}$.

\section{Cell Counting Kit-8 (CCK-8) detection}

The stably transfected NSCLC cells were seeded in 96 -well plates $\left(5 \times 10^{3}\right.$ cells/well) containing $100 \mu \mathrm{L}$ of DMEM medium (10\% FBS) and were cultured at $37{ }^{\circ} \mathrm{C}$,
$5 \% \mathrm{CO}_{2}$. After being cultured for 24, 48, and $72 \mathrm{~h}$, CCK-8 reagent $(10 \mu \mathrm{L})$ was added into each well for 4-h incubation at $37^{\circ} \mathrm{C}$. Plates were placed on a microplate reader (Biotek Instruments, Winooski, VT, USA) to measure the optical density (OD) value of each well at $450 \mathrm{~nm}$ wavelength. In addition, the OD value of the cells just after inoculation into 96-well plates was detected using the same method and recorded as the OD value at $0 \mathrm{~h}$.

\section{Cell cycle}

The cells that were stably transfected were fixed with $70 \%$ cold ethanol for $12 \mathrm{~h}$ at $4{ }^{\circ} \mathrm{C}$ in 6 -well plates $\left(1 \times 10^{5}\right.$ cells/well $)$ and were washed with phosphate-buffered saline (PBS) after being centrifuged for $5 \mathrm{~min}$ at 1,200 r/min. Ribonuclease (RNase; $200 \mu \mathrm{L}$ ) was used to incubate cells for $30 \mathrm{~min}$ at $37^{\circ} \mathrm{C}$, after which propidium iodide (PI) being used to incubate cells for $30 \mathrm{~min}$ at room temperature in the dark. Cell cycle distribution was analyzed by flow cytometry (Beckman Coulter Inc., Brea, CA, USA).

\section{Wound-healing assay}

After transfection, the cells were inoculated into 6-well plates $\left(1 \times 10^{5}\right.$ cells/well $)$ and cultured at $37{ }^{\circ} \mathrm{C}, 5 \% \mathrm{CO}_{2}$ for $24 \mathrm{~h}$ to allow cells to attach to the bottom of each well. A $200-\mu \mathrm{L}$ pipette tip was used to draw a straight line at the bottom of each hole. The original wound width was observed under an inverted microscope. The residual DMEM medium (10\% FBS) in each well was replaced by fresh DMEM medium (10\% FBS). The cells were incubated at $37{ }^{\circ} \mathrm{C}, 5 \% \mathrm{CO}_{2}$ for $24 \mathrm{~h}$, and then the plates were removed to observe the final wound width under the inverted microscope. The relative wound width was calculated as follows: relative wound width $=$ original wound width/the final wound width.

\section{Transwell experiment}

Cell invasion ability was assessed by Transwell experiment using Transwell cell culture inserts ( $8 \mu \mathrm{m}$ pores). Matrigel (Corning Inc., Corning, NY, USA) was evenly spread on the Transwell chamber microfilm before the cells in serum-free DMEM suspensions $\left(5 \times 10^{4}\right.$ cells/insert $)$ were inoculated into the inserts. DMEM medium with $10 \% \mathrm{FBS}$ was added into the lower chambers. At $37{ }^{\circ} \mathrm{C}, 5 \% \mathrm{CO}_{2}$, cells were incubated for $48 \mathrm{~h}$, and then the noninvading cells were 
scraped off by cotton swab. The invading cells attached to the lower surface of the membrane were fixed with $4 \%$ paraformaldehyde for $15 \mathrm{~min}$. Next, 15-min staining with crystal violet was also performed on these invading cells. The number of invading cells was counted in 5 random nonoverlapping fields under a microscope.

\section{Luciferase reporter gene assay}

Luciferase reporter vectors, including pMIR-LINC00511WT, pMIR-LINC00511-Mut, pMIR-GSPT1-WT, and pMIR-GSPT1-Mut, were constructed. A549 cells of the miR-625-5p NC group and the miR-625-5p mimic group were subjected to cotransfection with the above vectors. The luciferase activity of these cells was measured after 48-h cotransfection by double-luciferase assay system (Promega Corporation, Madison, WI, USA).

\section{$R N A$ isolation and quantitative reverse transcription polymerase chain reaction ( $q R T-P C R)$}

LINC00511, miR-625-5p, and GSPT1 mRNA in the patients' tissues and cells were measured by qRT-PCR. Total RNA in each tissue and cell sample was collected using TRIzol (Thermo Fisher Scientific). To synthesize complementary DNA (cDNA), the same amount of each RNA sample was subjected to reverse transcription reaction. The reverse transcription reaction was conducted using a PrimeScript RT reagent kit (Takara Bio, Kusatsu, Japan), and all operations were carried out according to the manufacturer's instructions. The expression level of the above 3 genes was then evaluated by qRT-PCR using a SYBR Premix Ex Taq kit (Takara Bio). An ABI-7900 thermal cycling instrument was provided by Applied Biosystems (Waltham, MA, USA). With glyceraldehyde 3-phosphate dehydrogenase (GAPDH) as an internal control, the $2^{-\triangle \Delta C T}$ method was used to analyze the relative expression of genes.

\section{Western blot}

The expression level of GSPT1 protein in the cells of the shNC and shLINC00511 groups was assessed by western blot. Total proteins in the cells of these 2 groups were obtained after a lysis buffer was used to lyse cells. A bicinchoninic acid (BCA) protein assay kit, provided by Pierce (Thermo Fisher Scientific), was used to determine the concentration of each sample. The same amount of each protein sample was subjected to separation by sodium dodecylsulphate polyacrylamide gel electrophoresis (SDSPAGE), and then these proteins were transferred electrically to the polyvinylidene difluoride (PVDF) membrane. After blocking with $5 \%$ skimmed milk powder, the PVDF membrane was incubated with polyclonal GSPT1 primary antibody (1:1,000 dilution; cat. no. 10763-1-AP; Proteintech Group, Rosemont, IL, USA) for $12 \mathrm{~h}$ at $4{ }^{\circ} \mathrm{C}$ and horseradish peroxidase (HRP) — conjugated secondary antibody (1:5,000 dilution; Proteintech Group) for $2 \mathrm{~h}$ at room temperature. The target bands were reflected by enhanced chemiluminescence (ECL) and evaluated by the Quantity One software (Bio-Rad Laboratories Inc., Hercules, CA, USA).

\section{Animal experiment}

Nude mice ( $\mathrm{n}=12$, male, 4-5 weeks old) were purchased from the Shanghai Experimental Animal Center of the Chinese Academy of Sciences. The mice were free to water and diet in a room at $25^{\circ} \mathrm{C}$ and were kept for 1 week in separate cages before subcutaneous injection. Six mice were randomly selected for subcutaneous injection of A549 cells of the shNC group $\left(2 \times 10^{5}\right.$ cells). The other 6 mice underwent subcutaneous injection of A549 cells of the shLINC00511 group $\left(2 \times 10^{5}\right.$ cells). After injection, all mice were returned to the cage. At day 7, 14, 21, and 28 after injection, the tumor volume of each mouse was calculated by measuring the long and short diameters of the tumors. At day 28, the tumor tissues were obtained after the mice were sacrificed.

Experiments were performed under a project license (No. CZLS2021260-A) granted by the ethics board of Chongqing University Cancer Hospital, in compliance with Chongqing University Cancer Hospital guidelines for the care and use of animals.

\section{Immunobistochemistry}

Tumor tissues were embedded in paraffin and cut into slices with a thickness of $6 \mu \mathrm{m}$. The slices were dewaxed with xylene and rehydrated with gradient alcohol. After a rinsing in deionized water for $2 \mathrm{~min}$, the slices were placed in the repair kit for antigen retrieval with a $0.01 \mathrm{M}$ citrate buffer. $\mathrm{H}_{2} \mathrm{O}_{2}$ solution ( $3 \%$, dissolved in deionized water) was used to incubate the slices for $15 \mathrm{~min}$ to block endogenous peroxidase. After being incubated with $5 \%$ goat serum for $30 \mathrm{~min}$, the slices were incubated with primary antibodies 


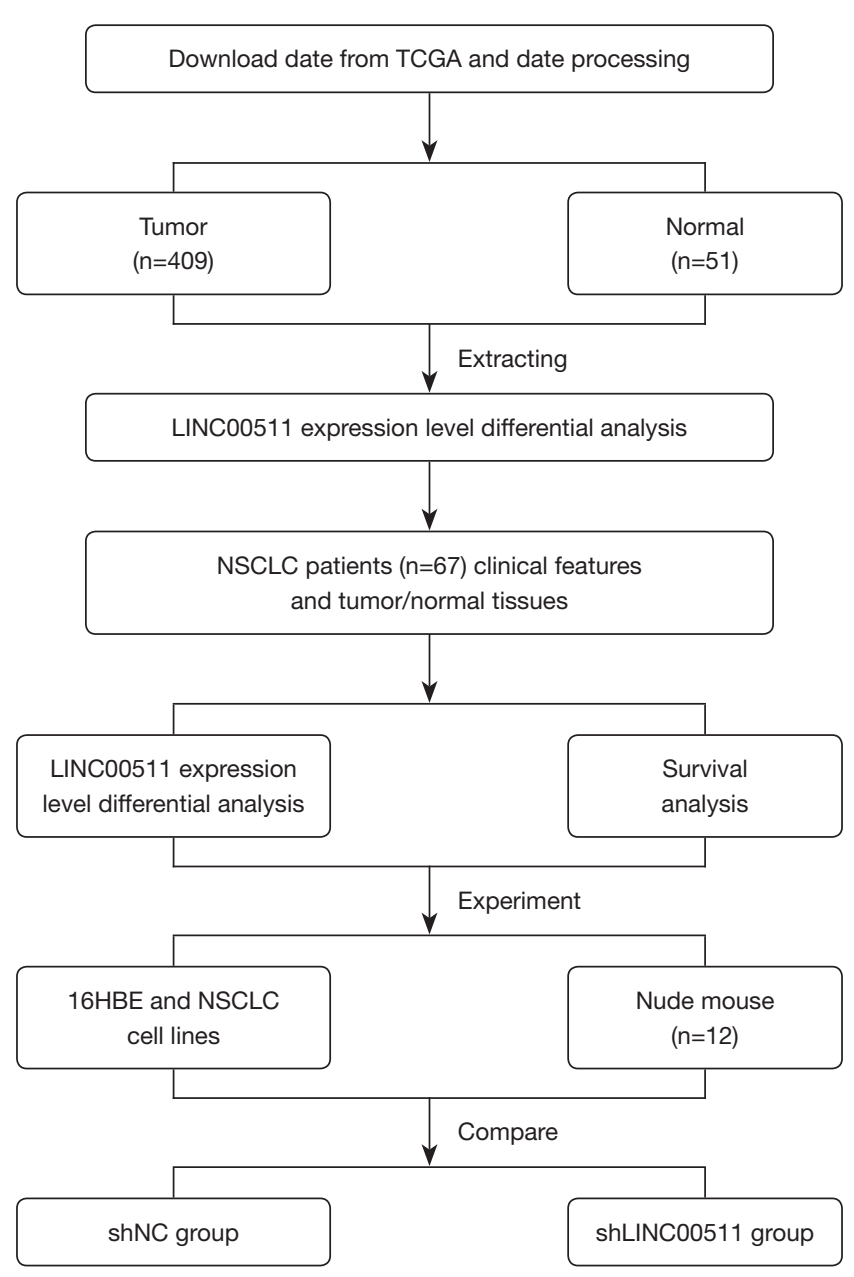

Figure 1 Study flowchart.

(mouse anti-human Ki67 monoclonal antibody and mouse anti-rabbit GSPT1 antibody; 1:100 dilution; Santa Cruz Biotechnology, Inc., Santa Cruz, CA, USA) at $4{ }^{\circ} \mathrm{C}$ for $12 \mathrm{~h}$ and an HRP-labeled secondary antibody (1:200 dilution; Beijing Zhongshang Jinqiao Biotechnology Co., Ltd., Beijing, China) at room temperature for $30 \mathrm{~min}$. PBS was used to wash these slices. DAB (3,3'-Diaminobenzidine) solution and hematoxylin were used sequentially to stain slices. Finally, the slices were observed under a microscope after being sealed with neutral resin. Cells with brownyellow particles were identified as Ki67- and GSPT1positive expression cells.

\section{Statistical analysis}

All experiments involved in this paper were performed independently at least 3 times, and the data are presented as mean and SD. A 2-tailed Student's $t$-test was used to analyze the difference between the shNC group and shLINC00511 group. Statistical analysis was performed using the SPSS 19.0 software (IBM Corp., Armonk, NY, USA). A result of $\mathrm{P}<0.05$ was considered to be statistically significant.

\section{Results}

\section{Upregulated LINC00511 in NSCLC was associated with poor prognosis in patients}

A workflow of the study is shown in Figure 1. TCGA analysis was performed by collecting 501 cancer samples and 49 normal samples from LUSC patients. Dramatically higher LINC00511 expression was found in the 501 cancer samples when compared with that in the 49 normal 

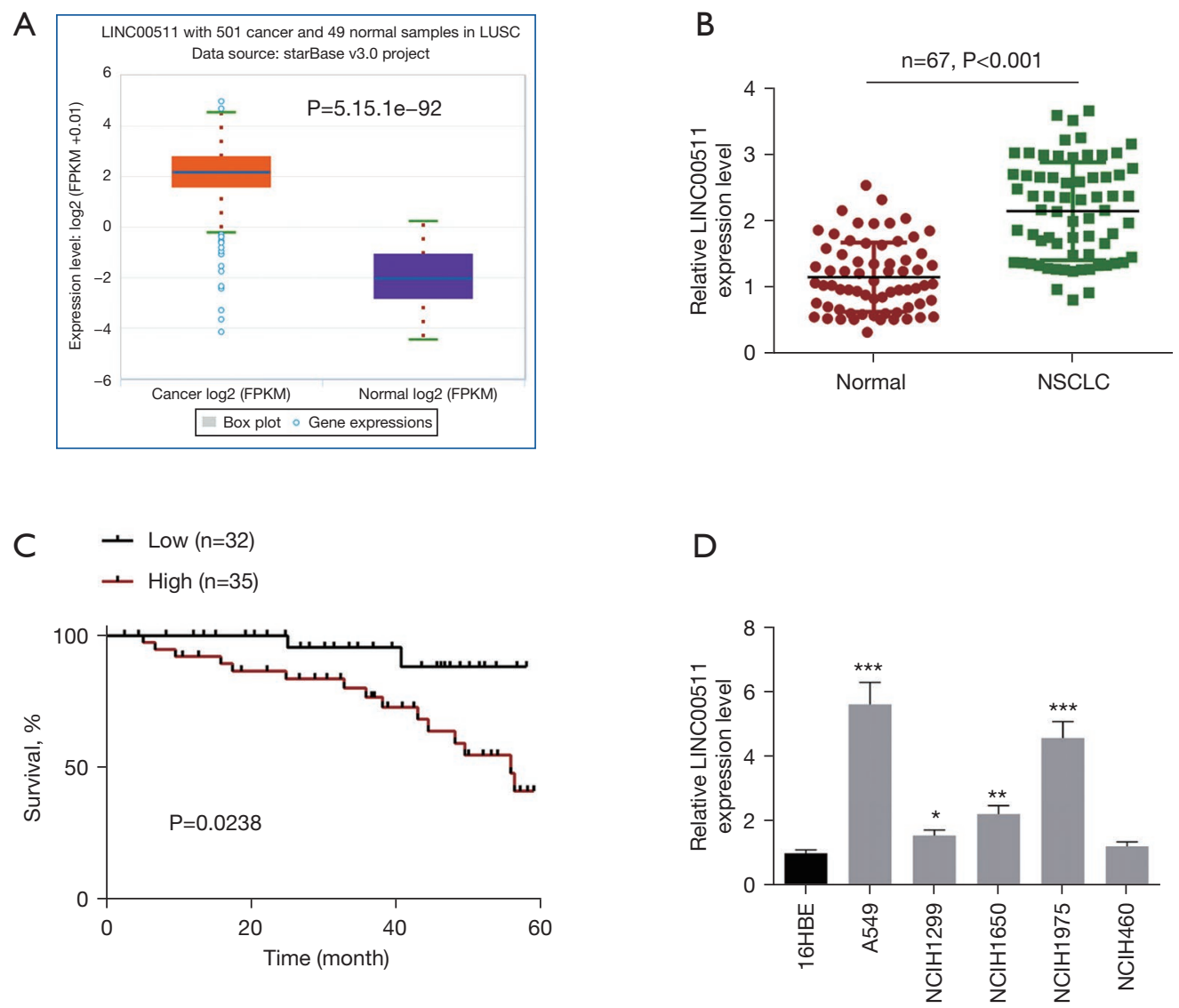

Figure 2 LINC00511 was up-regulated in NSCLC. (A) TCGA analysis indicated much higher LINC00511 expression in LUSC tissues than normal tissues. (B) LINC00511 was obviously up-regulated in NSCLC tissues than that in normal tissues. (C) High LINC00511 expression was associated with lower 5-year survival rate. (D) LINC00511 expression was much elevated in NSCLC cell lines than that in 16HBE cell line. *, $\mathrm{P}<0.05$; **, $\mathrm{P}<0.01$; **, $\mathrm{P}<0.001$ when compared with $16 \mathrm{HBE}$ cell line. NSCLC, non-small cell lung cancer; TCGA, The Cancer Genome Atlas; LUSC, lung squamous cell carcinoma.

samples $(\mathrm{P}<0.001 ;$ Figure $2 A)$. Clinically, we collected 67 pairs of normal tissues and tumor tissues from patients with NSCLC and detected the relative LINC00511 expression in each sample. Elevated LINC00511 expression was also found in the NSCLC tissues relative to normal tissues $(\mathrm{P}<0.001$; Figure $2 B)$.

By analyzing the clinical features of the patients with NSCLC, we observed that high LINC00511 expression predicted poor prognosis. In the patients with NSCLC, high LINC00511 expression was associated with larger tumor size $(\mathrm{P}<0.01)$, positive lymph node metastasis $(\mathrm{P}<0.01)$, and advanced TMN stage $(\mathrm{P}<0.05$; Table 1$)$. Moreover, patients with high LINC00511 expression ( $\mathrm{n}=35)$ were associated with a lower 5 -year survival rate than were those with a low LINC00511 expression $(\mathrm{n}=32 ; \mathrm{P}<0.05$;
Figure 2C).

LINC00511 expression in 6 cell lines (16HBE, A549, NCIH1299, NCIH1650, NCIH1975, and NCIH460) was detected by qRT-PCR (Figure 2D). The relative LINC00511 expression in the 16HBE and NCIH460 cell lines was comparable. However, compared with that of the 16HBE cell line, an increased relative LINC00511 expression was observed in the A549, NCIH1299, NCIH1650, and NCIH1975 cell lines $(\mathrm{P}<0.05, \mathrm{P}<0.01$, or $\mathrm{P}<0.001)$. Among these 4 cell lines (A549, NCIH1299, NCIH1650, and NCIH1975), the A549 and NCIH1975 cell lines showed a higher relative LINC00511 expression than did the NCIH1299 and NCIH1650 cell lines. Therefore, the A549 and NCIH1975 cell lines were selected as subjects for later research. 
Table 1 The clinical features of NSCLC patients

\begin{tabular}{|c|c|c|c|c|}
\hline Characteristics & $\begin{array}{c}\text { Number of } \\
\text { patients }\end{array}$ & $\begin{array}{l}\text { Low } \\
\text { LINC00511 } \\
\text { expression } \\
\text { ( } \leq \text { median) }\end{array}$ & $\begin{array}{c}\text { High } \\
\text { LINC00511 } \\
\text { expression } \\
\text { ( } \geq \text { median) }\end{array}$ & $P$ value \\
\hline Number & 67 & 32 & 35 & \\
\hline Age (years) & & & & 0.551 \\
\hline$<65$ & 34 & 16 & 18 & \\
\hline$\geq 65$ & 33 & 16 & 17 & \\
\hline Gender & & & & 0.086 \\
\hline Female & 35 & 20 & 15 & \\
\hline Male & 32 & 12 & 20 & \\
\hline Tumor size $(\mathrm{cm})$ & & & & 0.004 \\
\hline$\leq 3$ & 33 & 22 & 11 & \\
\hline$>3$ & 34 & 11 & 24 & \\
\hline Differentiation & & & & 0.568 \\
\hline Well & 38 & 18 & 20 & \\
\hline Poor & 29 & 14 & 15 & \\
\hline Smoking history & & & & 0.525 \\
\hline Smokers & 39 & 19 & 20 & \\
\hline Never & 28 & 13 & 15 & \\
\hline \multicolumn{2}{|c|}{ Lymph node metastasis } & & & 0.005 \\
\hline Negative & 30 & 20 & 10 & \\
\hline Positive & 37 & 12 & 25 & \\
\hline TMN stage & & & & 0.017 \\
\hline I & 36 & 22 & 14 & \\
\hline II/III/IV & 31 & 10 & 21 & \\
\hline
\end{tabular}

NSCLC, non-small cell lung cancer.

\section{Knockdown of LINC00511 was associated with significantly weakened proliferation, migration, and invasion of NSCLC cells}

The A549 and NCIH1975 cells underwent transfection, with the transfection efficacy assessed by qRT-PCR (shown in Figure $3 A$ ). Compared with that in the shNC group, the relative LINC00511 expression in the shLINC00511 group was clearly decreased $(\mathrm{P}<0.001)$. The CCK- 8 assay was an effective method for determining the proliferative capacity of cells. A prominently decreased OD 450 value at $72 \mathrm{~h}$ was found in the cells of the shLINC00511 group when compared with that of the shNC group $(\mathrm{P}<0.001$;
Figure 3B). Subsequently, the cell cycle was evaluated after transfection. The data illustrated that the percentage of cells in S phase in the shLINC00511 group was clearly decreased when compared with that in the shNC group (Figure 3C). Cell migration and invasion abilities were further assessed using a wound-healing assay and a Transwell experiment, respectively. As can be seen in Figure 3D,3E, a dramatically higher relative wound width and a remarkably lower invasive cell number were observed in the shLINC00511 group when compared with those in the shNC group $(\mathrm{P}<0.01$ or $\mathrm{P}<0.001)$.

miR-625-5p weakened the enhanced proliferation, migration, and invasion of NSCLC cells induced by LINC00511 overexpression

Luciferase reporters containing LINC00511-WT and LINC00511-Mut were constructed to verify whether miR625-5p was directly bound to LINC00511 (Figure 4A). Clearly decreased luciferase activity of the wild-type LINC00511 reporter (LINC00511-WT) was found in the A549 cells transfected with a miR-625-5p mimic when compared with that in the cells transfected with a miR625-5p NC $(\mathrm{P}<0.001)$. The transfection of the miR-625$5 \mathrm{p}$ mimic or the miR-625-5p NC did not obviously affect the luciferase activity of the LINC00511-Mut reporter (Figure 4B).

Subsequently, miR-625-5p expression in the tissue samples was determined. A significantly reduced relative miR-625-5p expression was found in the NSCLC tissues when compared with that in the normal tissues $(\mathrm{P}<0.001$; Figure $4 C$ ), and an apparent negative correlation was observed between relative miR-625-5p expression and relative LINC00511 expression in the NSCLC tissues $(\mathrm{P}<0.001 ;$ Figure $4 D)$. In vitro studies also indicated a clearly reduced relative miR-625-5p expression in the A549, NCIH1299, NCIH1650, and NCIH1975 cell lines when they were compared with the $16 \mathrm{HBE}$ cell line $(\mathrm{P}<0.05$, $\mathrm{P}<0.01$, or $\mathrm{P}<0.001)$. However, the relative miR-625-5p expression in the $16 \mathrm{HBE}$ and $\mathrm{NCIH} 460$ cell lines was comparable (Figure 4E).

Rescue experiments showed that when compared with those of the LIN-NC group, the A549 cells of the LINC00511 group exhibited a much higher OD 450 value at $72 \mathrm{~h}(\mathrm{P}<0.001)$, a higher percentage of cells in $\mathrm{S}$ phase, a lower relative wound width $(\mathrm{P}<0.001)$, and a remarkably higher invasive cell number $(\mathrm{P}<0.001)$. However, when compared with those of the LINC00511 group, the A549 
A

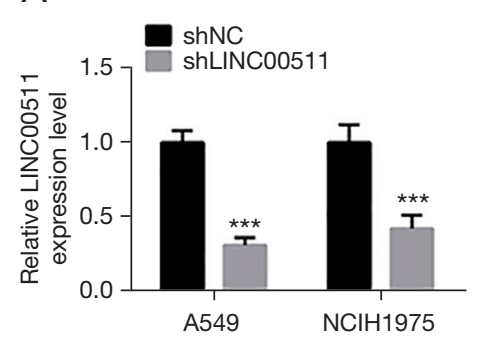

C

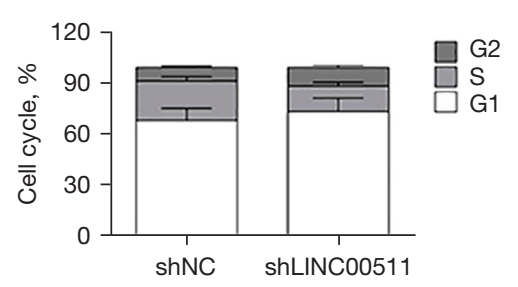

D ShNC

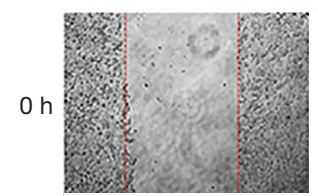

$24 \mathrm{~h}$

A549
B

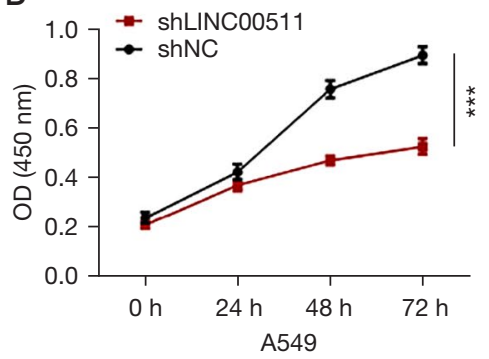

$\mathrm{NClH} 1975$

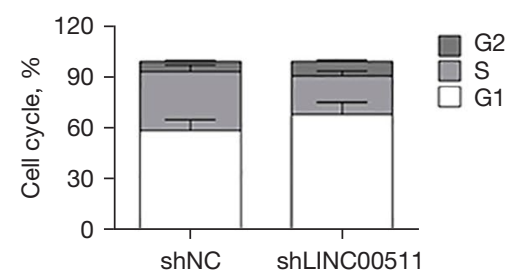

shNC

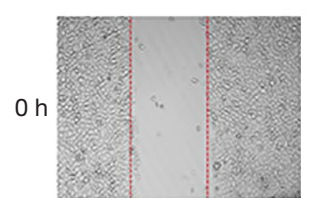

shLINC00511
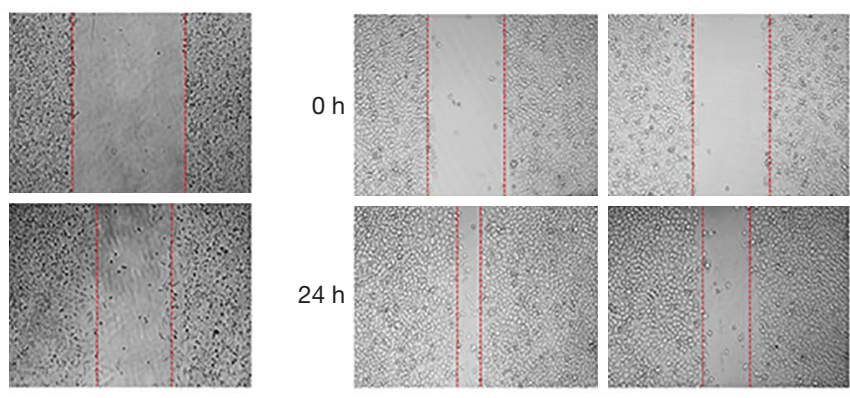

$\overline{\mathrm{NClH} 1975}$

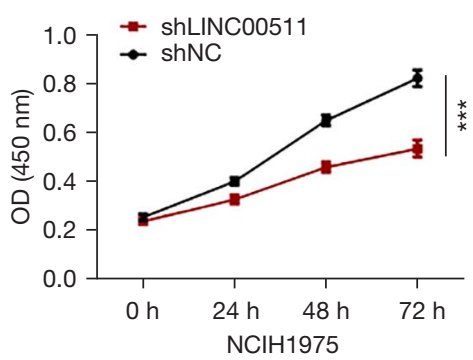

$\mathrm{NClH} 1975$
E ShNC ShLINC00511

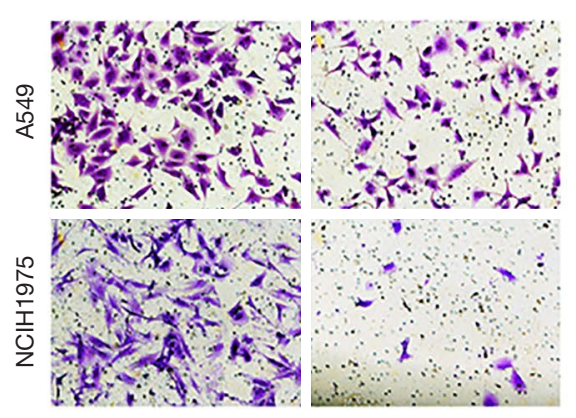

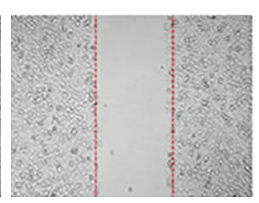

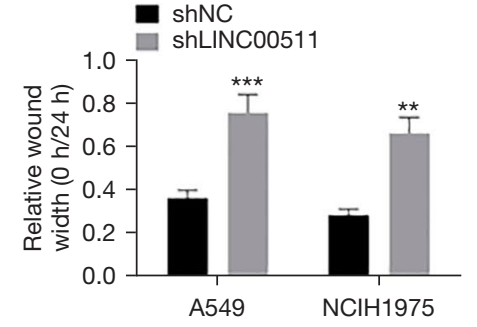

Figure 3 Significantly weakened proliferation, migration and invasion of NSCLC cells by knockdown of LINC00511. (A) Compared with shNC group, the relative LINC00511 expression in shLINC00511 group was evidently decreased. (B) Prominently declined OD 450 value was found in cells of shLINC00511 group at $72 \mathrm{~h}$ when compared with shNC group. (C) Compared with the percentage of cells in S phase of shNC group, it was obviously decreased in cells of shLINC00511 group. (D) Dramatically higher relative wound width was observed in shLINC00511 group when compared with that in shNC group. (E) Remarkably lower invasive cell number was observed in shLINC00511 group when compared with that in shNC group. ${ }^{* *}, \mathrm{P}<0.01$; ${ }^{* * *}, \mathrm{P}<0.001$ when compared with shNC group. Staining method: crystal violet. Scale bar: $100 \mu \mathrm{m}$. NSCLC, non-small cell lung cancer; NC, negative control; OD, optical density. 
cells of the LINC00511 + miR-625-5p mimic group exhibited a significantly decreased OD 450 value at $72 \mathrm{~h}$ $(\mathrm{P}<0.001)$, a reduced percentage of cells in $\mathrm{S}$ phase, a dramatically higher relative wound width $(\mathrm{P}<0.01)$, and a markedly lower invasive cell number $(\mathrm{P}<0.01$; Figure $4 F-4 I)$.

\section{GSPT1 knockdown inbibited the enbanced proliferation, migration, and invasion of NSCLC cells caused by LINC00511 overexpression}

The predicted binding sites of GSPT1 on miR-625-5p are displayed in Figure 5A. When compared with that of the miR-625-5p NC group, significantly reduced luciferase activity of the GSPT1-WT reporter was observed in the A549 cells of the miR-625-5p mimic group $(\mathrm{P}<0.001)$. The luciferase activity of the GSPT1-Mut reporter was comparable between the A549 cells of the miR-625-5p NC group and the miR-625-5p mimic group (Figure 5B).

In the NSCLC tissues, a much higher relative GSPT1 expression was presented when compared with that in normal tissues $(\mathrm{P}<0.001$; Figure 5C). Pearson's correlation coefficient illustrated that the relative GSPT1 expression level in the NSCLC tissues was positively correlated with the relative LINC00511 expression level $(\mathrm{P}<0.0001)$ but was negatively correlated with the relative miR-625-5p expression level $(\mathrm{P}<0.001$; Figure $5 D, 5 E)$. The relative GSPT1 expressions in the NCIH460 and 16HBE cell lines were comparable. However, the other 4 NSCLC cell lines (A549, NCIH1299, NCIH1650, and NCIH1975) showed a much higher relative GSPT1 expression than did the $16 \mathrm{HBE}$ cell line $(\mathrm{P}<0.05, \mathrm{P}<0.01$, or $\mathrm{P}<0.001$; Figure $5 F)$.

After transfection, GSPT1 protein expression in the A549 and NCIH1975 cell lines was detected by western blot. As shown in Figure 5G, the A549 and NCIH1975 cells of the shLINC00511 group showed a remarkably decreased relative GSPT1 protein expression compared with the shNC group $(\mathrm{P}<0.01$ or $\mathrm{P}<0.001)$. Rescue experiments revealed that when compared with those of the LIN-NC group, the A549 cells of the LINC00511 group displayed a much higher OD 450 value at $72 \mathrm{~h}(\mathrm{P}<0.001)$, a higher percentage of cells in $\mathrm{S}$ phase, a markedly lower relative wound width $(\mathrm{P}<0.001)$, and a significantly higher invasive cell number $(\mathrm{P}<0.001)$. However, when compared with the A549 cells of the LINC00511 group, those of the LINC00511 + shGSPT1 group exhibited a prominently declined OD 450 value at $72 \mathrm{~h}(\mathrm{P}<0.001)$, a much lower percentage of cells in $\mathrm{S}$ phase, a dramatically higher relative wound width $(\mathrm{P}<0.001)$, and a remarkably lower invasive cell number $(\mathrm{P}<0.001$; Figure $5 H-5 K)$.

\section{LINC00511 knockdown inbibited NSCLC cell growth in vivo}

The transfected A549 cells of the shNC and shLINC00511 groups were injected subcutaneously into the backs of nude mice. Subcutaneous tumor tissues after 28 days are shown in Figure 6A. The tumor volume at day 7, 14, 21, and 28 after injection was measured, and the results are shown in Figure 6B. On the 28th day after injection, the tumor volume of the shLINC00511 group was markedly lower than that of the shNC group $(\mathrm{P}<0.05)$. Moreover, a much lower tumor weight was found in the shLINC00511 group when compared with that in the shNC group $(\mathrm{P}<0.001$; Figure $6 C$ ). Immunohistochemistry was performed on the tumor tissues of these 2 groups. When compared with that in the shNC group, an obviously lower Ki67 and GSPT1 positive cell number was evident in the tumor tissues of the shLINC00511 group (Figure 6D).

\section{Discussion}

lncRNAs have been shown to regulate the pathogenesis of human diseases, including tumors, by affecting epigenetic inheritance and transcription, as well as posttranscriptional levels (13). In addition, lncRNAs have been confirmed to affect the process of tumorigenesis, progression, and metastasis, and the disordered expression of lncRNAs is thought to be one of the major features of several malignant tumors (14). Many of the lncRNAs that have been discovered thus far show great potential in the clinical diagnosis and targeted therapy of human tumors $(15,16)$.

LINC00511 is a recently discovered lncRNA that acts as an oncogene in some human cancers $(9,10)$. To date, only one published article has documented the expression of LINC00511 in NSCLC. This previous study revealed that LINC00511 is prominently upregulated in NSCLC and is associated with poor prognosis, such as metastasis and advanced TMN stage. The results of this study were confirmed by the present research. In terms of mechanism, LINC00511 has been shown to promote the growth, migration, and invasion of NSCLC cells in vitro by inhibiting p57 expression via directly binding to EZH2 (17). Our research has uncovered a novel molecular mechanism, in which LINC00511 potentially promotes NSCLC 
A

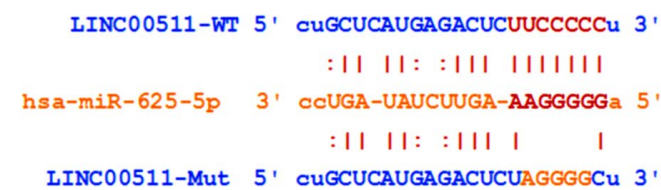

B

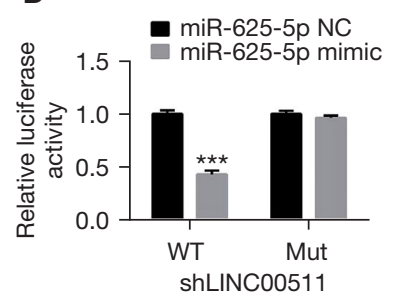

$\mathrm{F} . \mathrm{LNC}-\mathrm{NC}$

- LINC00511 + miR-625-5p mimic - LINC00511
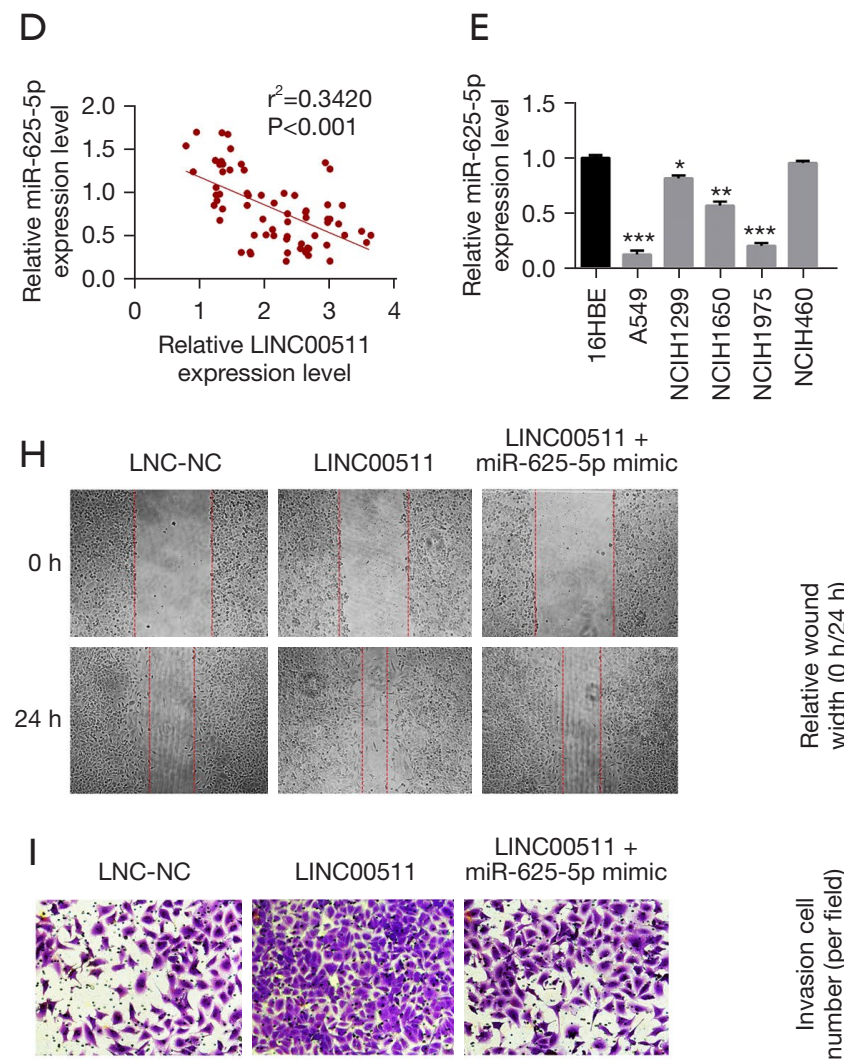

LINC00511+ miR-625-5p mimic
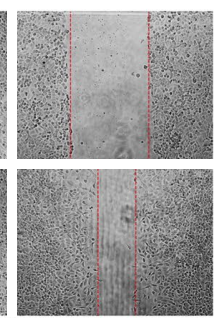

LINC00511 + miR-625-5p mimic

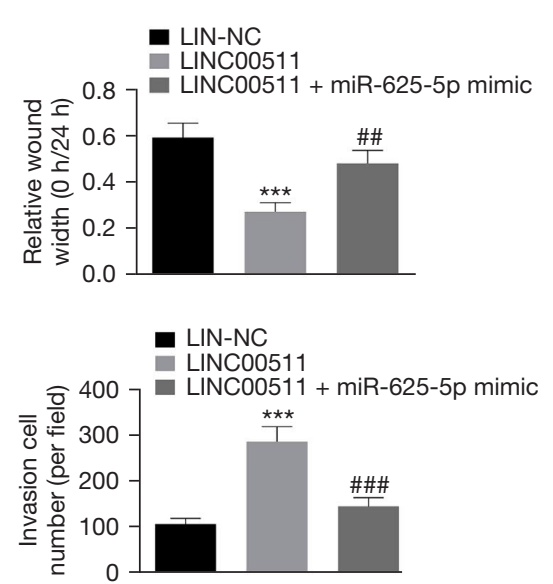

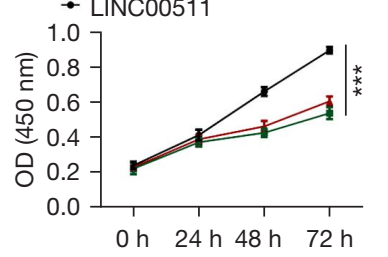

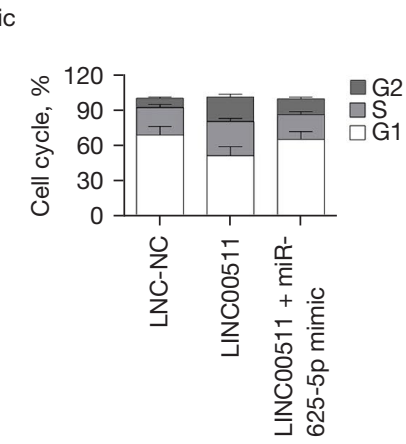

C

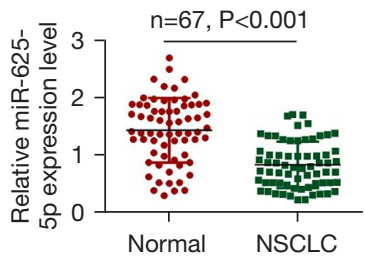

G

Figure 4 miR-625-5p weakened the enhanced proliferation, migration and invasion of NSCLC cells induced by LINC00511 overexpression. (A) The presentation of miR-625-5p binding sites on LINC00511. (B) Luciferase reporter gene assay. ${ }^{* * *}, \mathrm{P}<0.001$ when compared with miR-625-5p NC group. (C) Prominently reduced relative miR-625-5p expression was found in NSCLC tissues than that in normal tissues. (D) An apparent negative correlation was observed between relative miR-625-5p expression and relative LINC00511 expression in NSCLC tissues. (E) Obviously reduced relative miR-625-5p expression was found in A549, NCIH1299, NCIH1650 and NCIH1975 cell lines when compared with $16 \mathrm{HBE}$ cell line. * $\mathrm{P}<0.05$; **, $\mathrm{P}<0.01$; *** $\mathrm{P}<0.001$ when compared with $16 \mathrm{HBE}$ cell line. (F) Compared with LINC00511 group, A549 cells of LINC00511 + miR-625-5p mimic group had significantly decreased OD 450 value at 72 h. ***, $\mathrm{P}<0.001$ when compared with LINC00511 group. (G) Compared with LINC00511 group, A549 cells of LINC00511 + miR-625-5p mimic group showed evidently reduced percentage of cells in S phase. (H) Compared with LINC00511 group, A549 cells of LINC00511 + miR-625-5p mimic group exhibited markedly higher relative wound width. ***, $\mathrm{P}<0.001$ when compared with LIN-NC group; ${ }^{\# \#}$, $\mathrm{P}<0.01$ when compared with LINC00511 group. (I) Compared with LINC00511 group, A549 cells of LINC00511 + miR-625-5p mimic group had obviously lower invasive cell number. ${ }^{* * *}, \mathrm{P}<0.001$ when compared with LIN-NC group; ${ }^{\# \#}, \mathrm{P}<0.001$ when compared with LINC00511 group. Staining method: crystal violet. Scale bar: $100 \mu \mathrm{m}$. NSCLC, non-small cell lung cancer; NC, negative control; OD, optical density. 
A

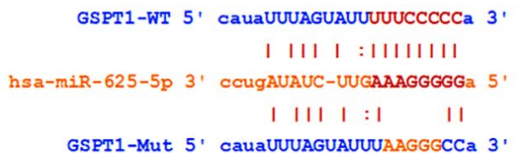

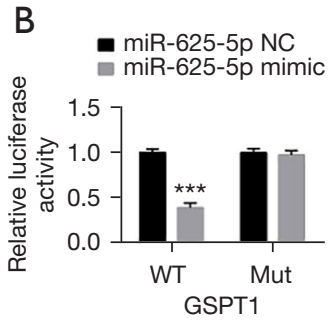

C

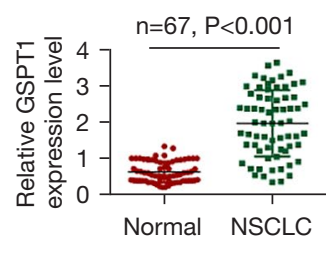

G

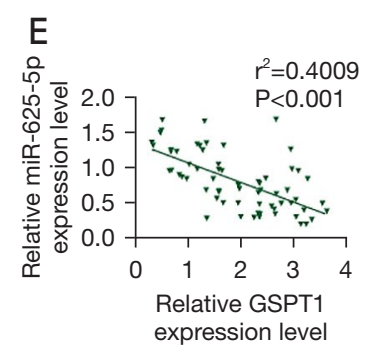

$\mathrm{H}$

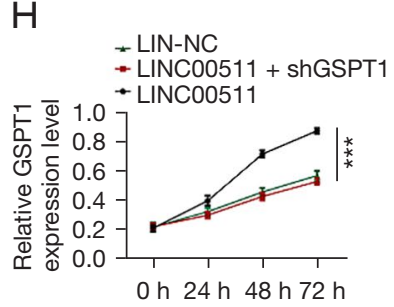

$\mathrm{F}$

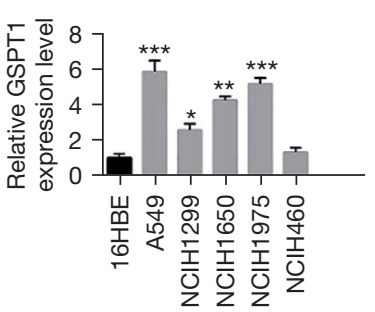

I

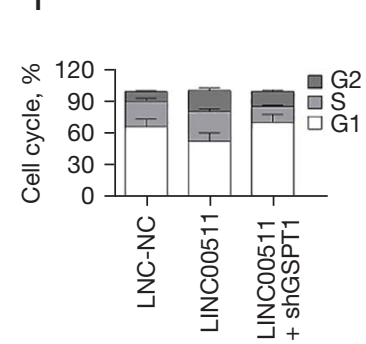

K

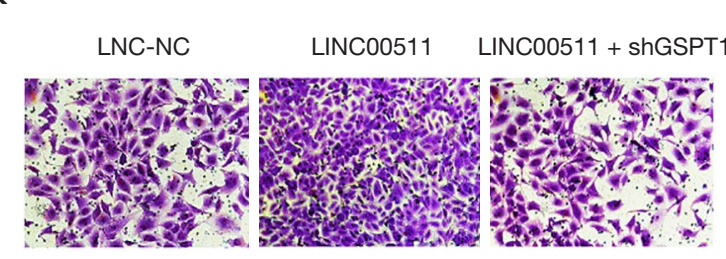

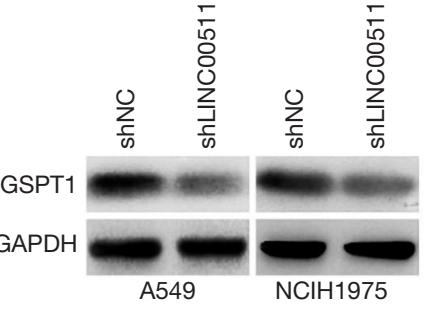

J
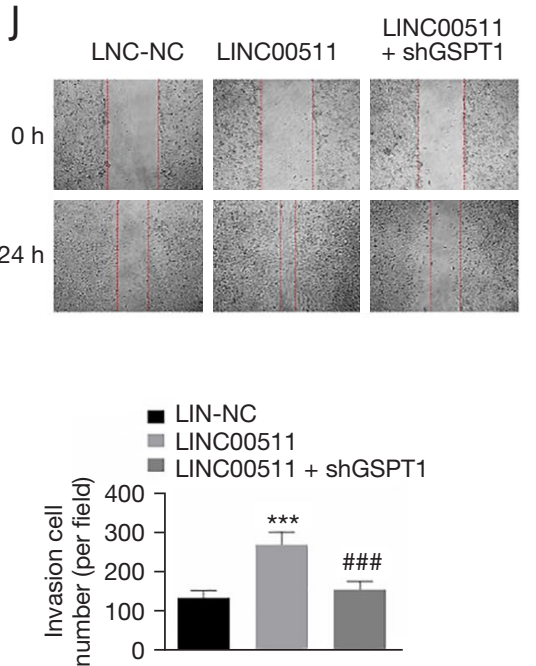

D
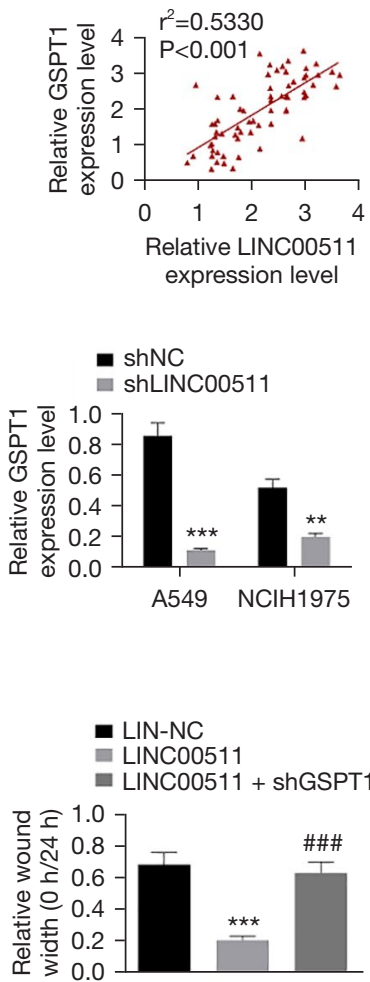

Figure 5 GSPT1 knockdown inhibited the enhanced proliferation, migration and invasion of NSCLC cells induced by LINC00511 overexpression. (A) The predicted binding sites of GSPT1 on miR-625-5p. (B) Luciferase reporter gene assay. ${ }^{* * *}, \mathrm{P}<0.001$ when compared with miR-625-5p NC group. (C) Relative GSPT1 expression was much higher in NSCLC tissues than that in normal tissues. (D,E) In NSCLC tissues, the relative GSPT1 expression level was positively correlated with relative LINC00511 expression level, but was negatively correlated with relative miR-625-5p expression level. (F) A549, NCIH1299, NCIH1650 and NCIH1975 cell lines showed much higher relative GSPT1 expression than $16 \mathrm{HBE}$ cell line. *, $\mathrm{P}<0.05$; ${ }^{* *}, \mathrm{P}<0.01$; ${ }^{* *}, \mathrm{P}<0.001$ when compared with $16 \mathrm{HBE}$ cell line. (G) A549 and NCIH1975 cells of shLINC00511 group had remarkably declined relative GSPT1 protein expression than those of shNC group. **, $\mathrm{P}<0.01$; ***, $\mathrm{P}<0.001$ when compared with shNC group. (H) A549 cells of LINC00511 + shGSPT1 group exhibited prominently declined OD 450 value at $72 \mathrm{~h}$ when compared with LINC00511 group. ${ }^{* * *}, \mathrm{P}<0.001$ when compared with LINC00511 group. (I) Compared with LINC00511 group, A549 cells of LINC00511 + shGSPT1 group had much lower percentage of cells in S phase. (J) A549 cells of LINC00511 + shGSPT1 group were with dramatically higher relative wound width that of LINC00511 group. ${ }^{* * *}$, $\mathrm{P}<0.001$ when compared with LIN-NC group; ${ }^{\# \#, ~} \mathrm{P}<0.001$ when compared with LINC00511 group. (K) Compared with LINC00511 group, A549 cells

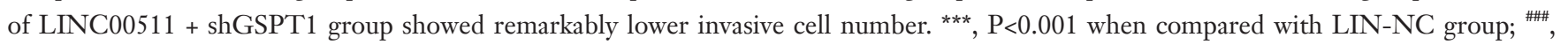
$\mathrm{P}<0.001$ when compared with LINC00511 group. Staining method: crystal violet. Scale bar: $100 \mu \mathrm{m}$. NSCLC, non-small cell lung cancer; NC, negative control; OD, optical density. 
A

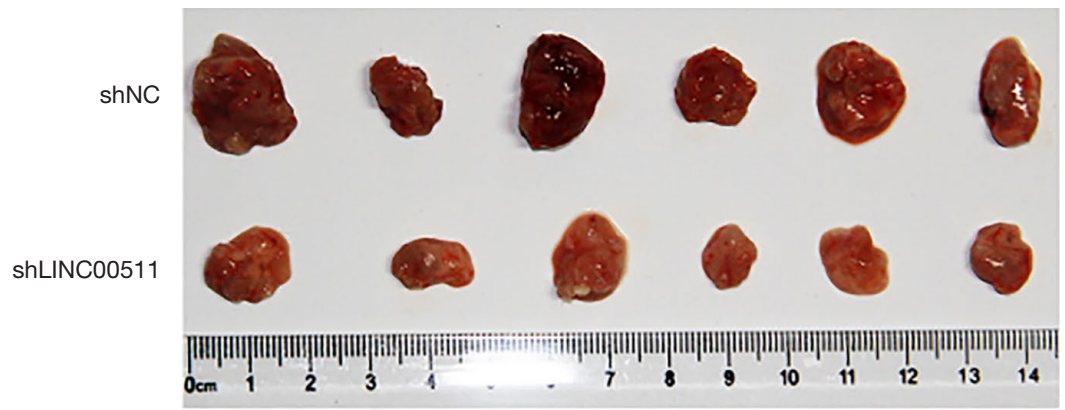

B

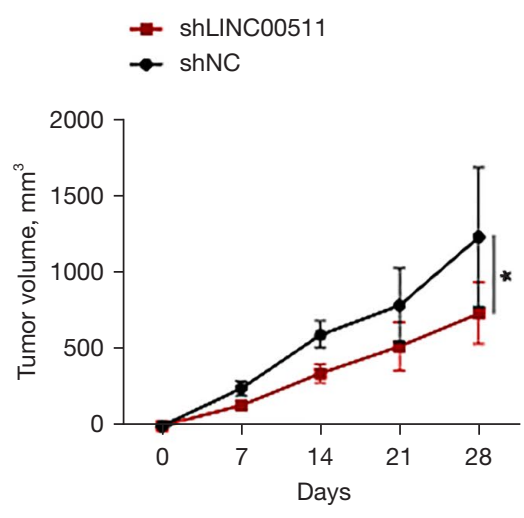

$\mathrm{D}$

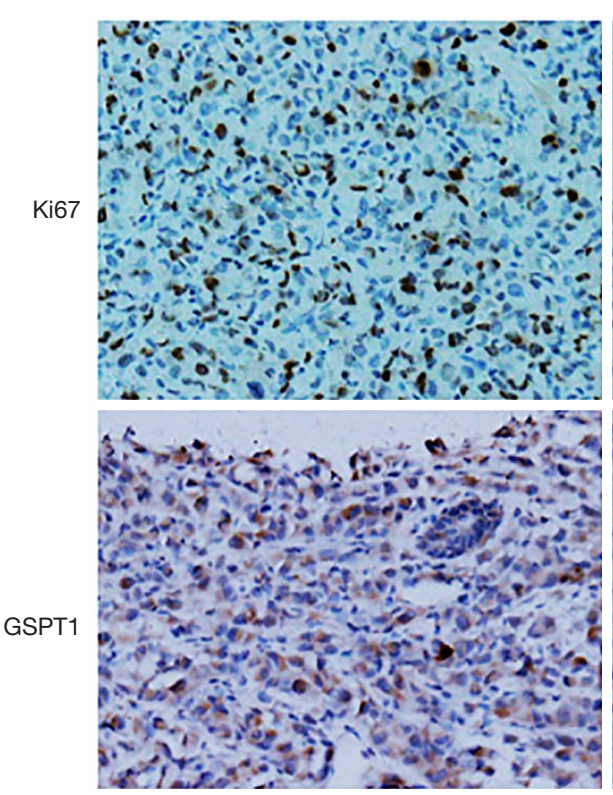

C $\square$ shNC ShLINC00511

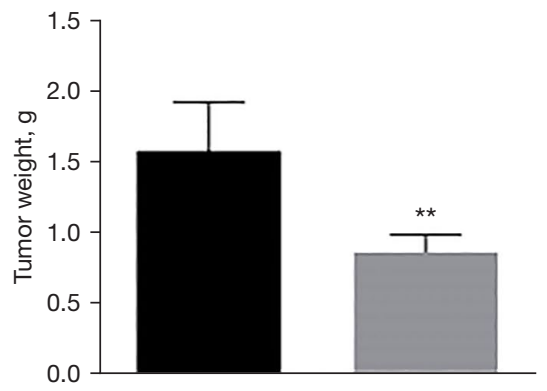

ShLINC00511

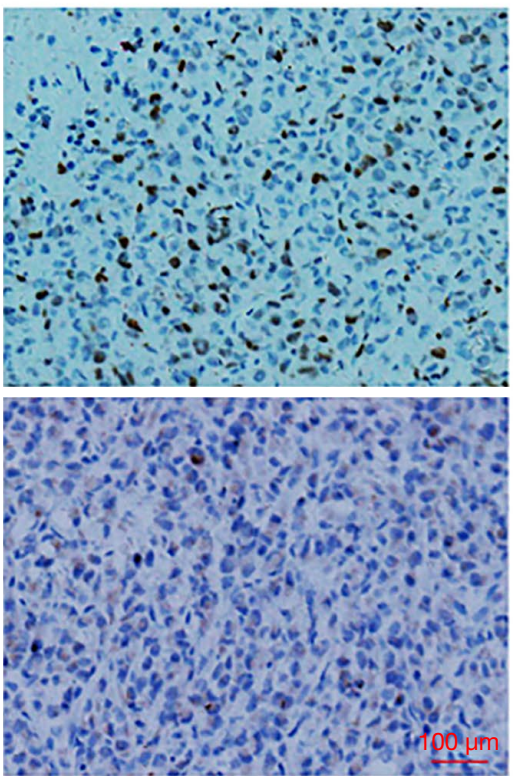

Figure 6 LINC00511 knockdown inhibited NSCLC cells growth in vivo. (A) Subcutaneous tumor tissues were obtained after 28 days. (B) On the 28th day after injection, the tumor volume of shLINC00511 group was markedly lower than that of shNC group. (C) Much lower tumor weight was found in shLINC00511 group when compared with shNC group. (D) Compared with shNC group, obviously lower Ki67 and GSPT1 positive cell number was occurred in tumor tissues of shLINC00511 group. *, $\mathrm{P}<0.05$; **, $\mathrm{P}<0.01$ when compared with shNC group. Staining method: DAB. Scale bar: $100 \mu \mathrm{m}$. NSCLC, non-small cell lung cancer; NC, negative control. 
progression by regulating the miR-625-5p/GSPT1 axis.

A large number of existing studies have suggested that the lncRNA-miRNA-mRNA regulatory network is an important means for lncRNAs to regulate human tumor development $(18,19)$. IncRNAs may cause overexpression of mRNA by competitively sponging miRNAs at the posttranscriptional level (20). miRNAs have been shown to have the function of tumor suppressors or oncogenes and to be critical regulators of apoptosis, invasion, cell cycle, and other cell biology behaviors $(21,22)$. This article indicated that miR-625-5p is a downstream gene of LINC00511 and that LINC00511 directly inhibits miR-625-5p expression by binding to the 3 '-UTR region. Previous cell biology behavioral studies have suggested that the overexpression of miR-625-5p could reverse the enhanced proliferation, migration, and invasion of NSCLC cells caused by LINC00511 overexpression. In one study (23), miR$625-5 \mathrm{p}$ was confirmed to be significantly downregulated in the plasma samples of asthma patients when compared with those of healthy participants used as a control. miR$625-5 \mathrm{p}$ also affected the onset of asthma by regulating the release of inflammatory cytokines such as tumor necrosis factor alpha (TNF- $\alpha$ ) and interleukin-10 (IL-10) (23). In addition, miR-625-5p expression was directly inhibited by circDENND2A, resulting in elevated migration and invasion abilities of glioma cells (24). Our data further confirm that miR-625-5p, a direct downstream gene of LINC00511, acts as a tumor suppressor in NSCLC.

GSPT 1 has been reported to be involved in tumorigenesis and is thought to be a proto-oncogene (25). The upregulated expression level of GSPT1 was previously discovered in breast cancer and intestinaltype gastric tumors (26). In recent years, Xiao et al. (27) noted dramatically increased GSPT1 expression in human colorectal cancer cells, with the proliferation and migration abilities of these cells declining after GSPT1 knockout. Data from Nair et al. (28) revealed that nicotine could stimulate the expression of GSPT1 in A549 cells, thereby inducing cell proliferation, invasion, and migration. The present paper demonstrates that miR-625-5p directly inhibits GSPT1, and that knockout of GSPT1 can suppress the proliferation, migration, and invasion of NSCLC cells induced by LINC00511.

In this study, animal in vivo studies were carried out through subcutaneous xenograft experiments in nude mice. Our results suggested that silencing of LINC00511 could suppress tumor growth in nude mice. Immunohistochemistry indicated decreased Ki67 and
GSPT1 protein expression in tumor tissues. Ki67 has been widely used in the exploration of human tumors as a marker for evaluating cell proliferation $(29,30)$; in our study, the Ki67 protein was closely related to cell proliferation, which could reflect the proliferative capacity of cells. Further data of animal experiments in vivo would provide a more reliable theoretical basis for LINC00511 in the clinical diagnosis and targeted treatment of NSCLC.

In summary, the results of our study demonstrated that LINC00511 is upregulated in NSCLC. Knockdown of LINC00511 can suppress NSCLC cell proliferation, migration, and invasion. In vivo experiments indicate that LINC00511 silencing can inhibit NSCLC cell growth in nude mice. Mechanically, lncRNA LINC00511 may promote NSCLC progression by targeting miR-625-5p/ GSPT. LINC00511 may be a potential diagnostic marker and therapeutic target for NSCLC.

\section{Acknowledgments}

We would like to thank AME Editing Service (https:// editing.amegroups.cn/) for polishing our paper.

Funding: None.

\section{Footnote}

Reporting Checklist: The authors have completed the ARRIVE reporting checklist. Available at http://dx.doi. org/10.21037/tcr-21-1468

Data Sharing Statement: Available at http://dx.doi. org/10.21037/tcr-21-1468

Peer Review File: Available at http://dx.doi.org/10.21037/tcr21-1468

Conflicts of Interest: All authors have completed the ICMJE uniform disclosure form (available at http://dx.doi. org/10.21037/tcr-21-1468). The authors have no other conflicts of interest to declare.

Ethical Statement: The authors are accountable for all aspects of the work in ensuring that questions related to the accuracy or integrity of any part of the work are appropriately investigated and resolved. The study was conducted in accordance with the Declaration of Helsinki (as revised in 2013). The study was approved by the Ethics Committee of Chongqing University Cancer Hospital. 
Written informed consent was taken from all individual participants. Experiments were performed under a project license (No. CZLS2021260-A) granted by the ethics board of Chongqing University Cancer Hospital, in compliance with Chongqing University Cancer Hospital guidelines for the care and use of animals.

Open Access Statement: This is an Open Access article distributed in accordance with the Creative Commons Attribution-NonCommercial-NoDerivs 4.0 International License (CC BY-NC-ND 4.0), which permits the noncommercial replication and distribution of the article with the strict proviso that no changes or edits are made and the original work is properly cited (including links to both the formal publication through the relevant DOI and the license). See: https://creativecommons.org/licenses/by-nc-nd/4.0/.

\section{References}

1. Tian W, Wang G, Liu Y, et al. The miR-599 promotes non-small cell lung cancer cell invasion via SATB2. Biochem Biophys Res Commun 2017;485:35-40.

2. Xu G, Shao G, Pan Q, et al. MicroRNA-9 regulates nonsmall cell lung cancer cell invasion and migration by targeting eukaryotic translation initiation factor 5A2. Am J Transl Res 2017;9:478-88.

3. Soria JC, Ohe Y, Vansteenkiste J, et al. Osimertinib in Untreated EGFR-Mutated Advanced Non-Small-Cell Lung Cancer. N Engl J Med 2018;378:113-25.

4. Zou Y, Zhong Y, Wu J, et al. Long non-coding PANDAR as a novel biomarker in human cancer: A systematic review. Cell Prolif 2018;51:e12422.

5. Li K, Sun D, Gou Q, et al. Long non-coding RNA linc00460 promotes epithelial-mesenchymal transition and cell migration in lung cancer cells. Cancer Lett 2018;420:80-90.

6. Shao M, Liu W, Wang Y. Differentially expressed LncRNAs as potential prognostic biomarkers for glioblastoma. Cancer Genet 2018;226-227:23-9.

7. Wang Y, Zhou J, Xu YJ, et al. Long non-coding RNA LINC00968 acts as oncogene in NSCLC by activating the Wnt signaling pathway. J Cell Physiol 2018;233:3397-406.

8. Zhan Y, Zang H, Feng J, et al. Long non-coding RNAs associated with non-small cell lung cancer. Oncotarget 2017;8:69174-84.

9. Zhao X, Liu Y, Li Z, et al. Linc00511 acts as a competing endogenous RNA to regulate VEGFA expression through sponging hsa-miR-29b-3p in pancreatic ductal adenocarcinoma. J Cell Mol Med 2018;22:655-67.

10. Li J, Li Y, Meng F, et al. Knockdown of long noncoding RNA linc00511 suppresses proliferation and promotes apoptosis of bladder cancer cells via suppressing Wnt/ $\beta$-catenin signaling pathway. Biosci Rep 2018;38:BSR20171701.

11. Ding J, Yang C, Yang S. LINC00511 interacts with miR765 and modulates tongue squamous cell carcinoma progression by targeting LAMC2. J Oral Pathol Med 2018;47:468-76.

12. Chen Y, Bao C, Zhang X, et al. Knockdown of LINC00511 promotes radiosensitivity of thyroid carcinoma cells via suppressing JAK2/STAT3 signaling pathway. Cancer Biol Ther 2019;20:1249-57.

13. Tang Y, Cheung BB, Atmadibrata B, et al. The regulatory role of long noncoding RNAs in cancer. Cancer Lett 2017;391:12-9.

14. Wang Y, Xue D, Li Y, et al. The Long Noncoding RNA MALAT-1 is A Novel Biomarker in Various Cancers: A Meta-analysis Based on the GEO Database and Literature. J Cancer 2016;7:991-1001.

15. Rodríguez Bautista R, Ortega Gómez A, Hidalgo Miranda A, et al. Long non-coding RNAs: implications in targeted diagnoses, prognosis, and improved therapeutic strategies in human non- and triple-negative breast cancer. Clin Epigenetics 2018;10:88.

16. Dai M, Chen S, Wei X, et al. Diagnosis, prognosis and bioinformatics analysis of lncRNAs in hepatocellular carcinoma. Oncotarget 2017;8:95799-809.

17. Sun CC, Li SJ, Li G, et al. Long Intergenic Noncoding RNA 00511 Acts as an Oncogene in Non-small-cell Lung Cancer by Binding to EZH2 and Suppressing p57. Mol Ther Nucleic Acids 2016;5:e385.

18. Ye S, Yang L, Zhao X, et al. Bioinformatics method to predict two regulation mechanism: TF-miRNA-mRNA and lncRNA-miRNA-mRNA in pancreatic cancer. Cell Biochem Biophys 2014;70:1849-58.

19. Zhang Y, Li Y, Wang Q, et al. Identification of an lncRNA miRNA mRNA interaction mechanism in breast cancer based on bioinformatic analysis. Mol Med Rep 2017;16:5113-20.

20. Du Y, Weng XD, Wang L, et al. LncRNA XIST acts as a tumor suppressor in prostate cancer through sponging miR-23a to modulate RKIP expression. Oncotarget 2017;8:94358-70.

21. Chen CZ. MicroRNAs as oncogenes and tumor suppressors. N Engl J Med 2005;353:1768-71.

22. Suzuki Y, Kim HW, Ashraf M, et al. Diazoxide potentiates 
mesenchymal stem cell survival via NF-kappaB-dependent miR-146a expression by targeting Fas. Am J Physiol Heart Circ Physiol 2010;299:H1077-82.

23. Dong X, Xu M, Ren Z, et al. Regulation of CBL and ESR1 expression by microRNA-22 3p, 513a-5p and 625$5 \mathrm{p}$ may impact the pathogenesis of dust mite-induced pediatric asthma. Int J Mol Med 2016;38:446-56.

24. Su H, Zou D, Sun Y, et al. Hypoxia-associated circDENND2A promotes glioma aggressiveness by sponging miR-625-5p. Cell Mol Biol Lett 2019;24:24.

25. Malta-Vacas J, Ferreira P, Monteiro C, et al. Differential expression of GSPT1 GGCn alleles in cancer. Cancer Genet Cytogenet 2009;195:132-42.

26. Malta-Vacas J, Aires C, Costa P, et al. Differential expression of the eukaryotic release factor 3 (eRF3/ GSPT1) according to gastric cancer histological types. J

Cite this article as: Cheng $\mathrm{Y}$, Wang $\mathrm{S}, \mathrm{Mu} \mathrm{X}$. Long noncoding RNA LINC00511 promotes proliferation, invasion, and migration of non-small cell lung cancer cells by targeting miR625-5p/GSPT1. Transl Cancer Res 2021;10(12):5159-5173. doi: $10.21037 /$ tcr-21-1468
Clin Pathol 2005;58:621-5.

27. Xiao R, Li C, Chai B. miRNA-144 suppresses proliferation and migration of colorectal cancer cells through GSPT1. Biomed Pharmacother 2015;74:138-44.

28. Nair S, Bora-Singhal N, Perumal D, et al. Nicotinemediated invasion and migration of non-small cell lung carcinoma cells by modulating STMN3 and GSPT1 genes in an ID1-dependent manner. Mol Cancer 2014;13:173.

29. Zhou $\mathrm{Y}, \mathrm{Hu} \mathrm{W}$, Chen $\mathrm{P}$, et al. Ki67 is a biological marker of malignant risk of gastrointestinal stromal tumors: A systematic review and meta-analysis. Medicine (Baltimore) 2017;96:e7911.

30. Zhang X, Jones A, Jenkins SM, et al. Ki67 Proliferative Index in Carcinoid Tumors Involving Ovary. Endocr Pathol 2018;29:43-8. 